\title{
Distribusi Barang Melalui Asia Tenggara yang Berlatar Politis
}

Yusmaini Eriawati

Keywords: Chinese manuscript, exchange, trade

How to Cite:

Eriawati, Y. Distribusi Barang Melalui Asia Tenggara Yang Berlatar Politis.

Berkala Arkeologi, 14(2), 156-162. https:// doi.org/10.30883/jba.v14i2.715

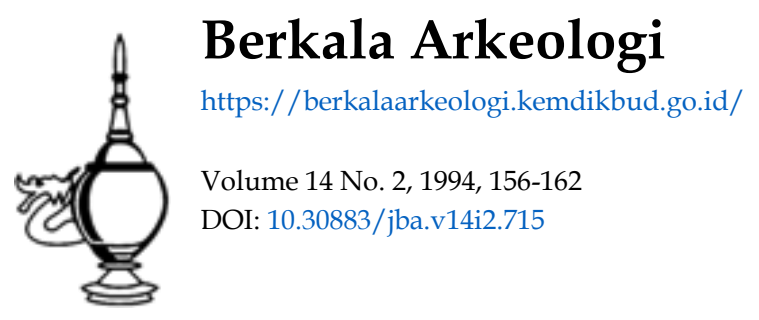

\section{c) (7)(2) (2)}

This work is licensed under a Creative Commons Attribution-NonCommercial-ShareAlike 4.0 International License. 


\title{
DISTRIBUSI BARANG MELALUI ASIA TENGGARA YANG BERLATAR POLITIS
}

\author{
Yusmaini Eriawati \\ (Pusat Penelitian Arkeologi Nasional)
}

\section{Pendahuluan}

Data tekstual dari sumber-sumber sejarah lokal di Indonesia berupa prasasti dan karya sastra dapat dikatakan telah memberikan pemaparan yang cukup lengkap mengenai berbagal aspek kehidupan pada masa lalu. Akan lebih lengkap lagi jika data tersebut dipadukan dan diperbandingkan dengan data dari sumber-sumber tertulis asing, baik dari Cina, Eropa maupun Arab. Hal tersebut untuk mencoba memahami sejarah kuna, terutama sejarah kuna Indonesia.

Sesuai dengan salah satu ruang lingkup bahasan yang terdapat dalam sinopsis Seminar Evaluasi Data dan Interpretasi Baru Sejarah Indonesia Kuna Dalam Rangka Purna Bakti Drs. M.M. Soekarto Karto Atmodjo pada butir ketıga, yaitu Penyajian interpretasi kesejarahan yang lebih luas atas berbagai sektor kehidupan masyarakat indonesia kuna berdasarkan kajian data tekstual, dalam penulısan makalah ini data yang diambil bersumber dari catatan berita asing, khususnya berita Cina yang ditulis sekitar abad V - XVI M, masa Hindu-Buda di Indonesia. Tema kajian yang dipilih yaitu mengenai distribusi atau pertukaran barang.

Sebagian besar penelitian yang memasalahkan distribusi atau pertukaran barang, khususnya yang terjadi di wilayah Asia Tenggara selalu dikaitkan dengan aspek ekonomi, yaitu perdagangan. Hal tersebut karena barang yang dipertukarkan sering dianggap sebagai barangbarang komoditi. Kecenderungan seperti itu cukup dimaklumi melihat hubungan antar negaranegara di laut selatan, sebagian besar diawali dengan adanya pertukaran barang dari jenis komoditi. Sekaligus karena banyaknya barang yang tersedia di wilayah Asia tenggara.

Beberapa uraian sumber asing Cina, menunjukkan adanya aspek lain yang melatari adanya tukar-menukar (pengiriman) barang antara negara Cina dengan negara-negara di wilayah laut selatan, yaitu pertukaran barang dengan tujuan politis

\section{Data Kajian}

\subsection{Sumatera}

Berita Cina Chu-fan-chi, yang ditulis oleh Chau Ju Kua banyak menguraikan mengenai negerı-negeri di Asia Tenggara yang mengirimkan duta dengan membawa barang baik sebagaı hadiah maupun upeti ke berbagai negara besar seperti Cina, Sriwijaya, dan negara Annam.

Sriwijaya, menurut sumber Cina, mula menjalin hubungan dengan Cina sejak masa t"ien-yu dari dinasti Tang (904-907). Selanjutnya pada masa Kieng-lung (960-963) negeri ini mengirim duta dengan membawa barang untuk raja Cina sebanyak tiga kali. Selain adanya uraıan mengenai pengiriman duta serta pemberian barang tersebut, raja dari Sriwijaya pun mengadakan hubungan dengan mengirim surat yang mengatakan bahwva negerinya diserbu oleh kerajaan Sho-p'o sekitar tahun ke-3 masa shunhua (992) (Hirth.1962). Para penelitı sejarah kuna menginterpretasikan Sho-p'o ini dengan salah satu kerajaan di Jawa

Antara tahun 1004--1022 dan tahun 1078-1094, dikatakan bahwa raja dari Sumatera mengirim sejumlah utusan yang membawa barang untuk raja. Dari catatan Ling-wai-tai-ta diketahui bahwa pada tahun 1079 raja dari Chan-pei (negeri Jambi) mengirimkan barang untuk raja Cina, dan mengirim lagi pada tahun 1088

Selain uraian mengenai pengiriman duta serta kiriman barang ke Cina, Chau-Ju-Kua juga mencatat mengenai negeri-negerı bawahan Sriwijaya yang mengirimkan barang produksi lokal serta hasil tambang mereka secara tetap (setiap tahun), berupa emas, perak, gading gajah, dan sebagainya ke Sriwijaya serta ke Cina. Negerr. negeri yang dimaksud tersebut terletak tidak jauh dari negara Sriwijaya, yaitu negeri-negeri di wilayah Semenanjung Melayu, seperti Kwantan, Tembeling, Pahang, Lengkasuka, Beranang dan Lambri.

Pengiriman utusan serta barang dari pulau Sumatra ke Cina ini lebih banyak diuraikan dalam Sejarah dinastı Sung yang ditulis pada tahun 960-1279 (Groeneveld, 1960:62-68). Menurut sumber ini, pada akhir dinasti Tang (905) negerı besar di Sumatera mengirimkan duta yang membawa hadiah barang. Sekembalinya ke negaranya, pemimpin utusan tersebut dianugrahı gelar sebagai Jenderal Pasifik dan Jenderal uniuk Negeri-negeri Jauh oleh raja Cina

Pengirıman utusan serta hadiah barang ke negeri Cina menurut Sejarah dinasti Sung tersebut terus berlangsung pada tahun 960, 962, 971 
974,980,983, 985, dengan kiriman barang berupa gading gajah, lampu-lampu kristal, cula badak, dan sebagainya yang bermutu tinggi. Dicatat pula bahwa pada pengiriman tahun 962 tersebut, raja di Cina memberikan hadiah balasan berupa porselin-porselin putih, binatang Yak, perak, benang-benang sutera, serta dua set perlengkapan menunggang kuda. Pada tahun 988 tercatat pengiriman utusan yang membawa kiriman barang untuk raja Cina, tetapi pada tahun 992 didengar berita bahwa negeri ini telah diserbu oleh Sho-p'o

Pada tahun 1003 mulai lagi ada penginman utusan serta sejumlah barang ke Cina dari Sumatera. Dikatakan bahwa negeri yang mengi. rimkan utusan dengan membawa sejumlah barang ini memberikan do'a untuk raja Cina agar diberkati umur panjang. Selain itu, utusan inipun menyampaikan pesan raja mereka agar raja $\mathrm{Ci}$ na bersedia memberikan nama serta sebuah lonceng bagi candi Buddha. Raja Cina sangat bahagia dengan pemberian serta permintaan utusan itu, dan dengan senang hat memberikan candi tersebut (Cheng-tien-wan-shoul). Begitu pula utusan yang dikirim pada tahun 1003, sekembalinya mereka ke negerinya dianugrahi gelar Jenderal yang bijak dan disayangi rakyat

Informasi lain mengatakan, ada utusan yang datang membawa hadiah tahun 1008, meminta ijin kepada raja untuk pergi ke T'ai-shan, salah satu gunung suci di Cina. Selain itu juga ingin bertemu raja di balairung istana. Akhimya pada saat kembali, mereka membawa berbagai hadiah dari raja Cina.

Tahun 1017 datang utusan yang membawa surat bertinta mas serta hadiah berupa mutiara, gading, buku suci Buddha, serta budakbudak. Dengan titah raja, mereka dijinkan mengunjungi beberapa gedung utama di dalam istana dan bertemu kaisar. Begitu pula sekembali mereka ke negerinya, mereka dihadiahi sejumlah barang berharga oleh raja Cina. Bahkan utu san yang datang pada jaman pemerintahan Yuan-fung (1078--1085) membawa hadiah balasan untuk raja berupa 64000 ikatan uang logam, 15000 ikatan perak, serta gelar kehormatan untuk dua utusan yang datang tersebut

Dari catatan sejarah dinasti Ming (1368. 1643) dikatakan bahwa pada masa dinasti Sung (960-1279) negeri Sambo-tsai tidak henti-hentinya mengirimkan utusan yang membawa barang untuk raja Cina. Dari catatan Dinasti Ming ini pula diuraikan bahwa pada tahun 1370 raja yang disebut dengan Ma-ha-la-cha-pa-ta-pu (Maharaja Prabu) mengirimkan utusan dengan membawa surat yang ditulis dengan tinta mas serta hadiah berupa beruang hitam, burung kasuari, merak, kakak tua dengan berbagai wama, bermacammacam parfum, selimut dari wool, dan sebagai- nya. Hadiah ini dikirim dengan maksud agar raja Cina memberikan hadiah kembali berupa almanak kerajaan serta bahan-bahan sutera sesuai dengan derajat masing-masing. Pada waktu yang sama, barang-barang serta pedagang-pedagang milik mereka tiba di Chuan-chou diharuskan membayar pajak masuk. Tetapi atas perintah raja, mereka dibebaskan dari segala macam pembayaran. Tahun-tahun selanjutnya, raja sering mengirimkan utusan serta barang sebagai hadiah ucapan selamat tahun baru (1373-75).

Raja di Sumatera yang bergelar Maharaja Wuli (Ma-la-cha Wuif) menggantikan ayahnya yang meninggal tahun 1367. Raja ini mengirimkan utusan serta hadiah untuk raja Cina berupa cula-cula badak, burung kasuari, berbagai wama burung kakak tua, monyet-monyet putih, kulit kura-kura, kamper, kapur barus, dan sebagainya. Utusan tersebut mengatakan bahwa raja takut tidak bisa naik tahta tanpa adanya pengakuan dari negeri Cina. Oleh karena itu beliau meminta restu negara Cina dengan mengirimkan hadiah berupa barang-barang berharga tersebut. Raja Cina menyambut baik permintaan raja baru dari Sumatera itu dengan memberikan cap kerajaan dan restu sebagai raja di San-bo-tsai. Tetapi pada waktu itu temyata San-bo-tsai sudah diduduki oleh Jawa dan para utusan raja yang baru kembali dari Cina, dibunuh.

\subsection{Jawa}

Mengenai catatan negeri Jawa yang mengirimkan utusan dengan membawa barang untuk kerajaan Cina, tidak banyak yang dicatat dalam buku Chau-Ju-Kua. Dikatakan bahwa Jawa (She-p'o) pada tahun ke-12 raja Yuan-kia dari dinasti Sung masuk ke dalam pergaulan intemasional dengan Cina, tetapi pada tahun-tahun selanjutnya hubungan tersebut terputus. Pada masa raja Shun-hua (992), saat negeri di Jawa sedang membangun kedaulatannya, pada pesta pengukuhannya tersebut raja Jawa ini mengirim. kan utusan serta barang untuk raja Cina guna mendapat restu. Dari catatan Sung-shi diperoleh keterangan yang lebih rinci mengenai utusan dari Jawa yang dikirim tahun 992 dan 1109

Berita Cina lebih muda yang ditulis pada tahun 430 menceritakan adanya utusan yang datang dari Holotan sebuah negeri di She-p'o dengan membawa kain-kain India. Selain itu, utusan ini juga membawa sepucuk surat dari rajanya yang menerangkan bahwa negeri mereka diancam oleh negara-negara tetangganya, dan memohon agar raja di Cina memberi perlindungan dari jauh. Raja di negeri ini juga betharap agar Cina mengirimkan utusan ke negara-negara tersebut untuk minta agar mereka jangan mengancam Ho-lo-tan. Selanjutnya dimohonkan pula agar para permbesar di Kanton diperintahkan 
agar mengembalikan kapal-kapal Ho-lo-tan dan jangan merampok maupun merusaknya (Bambang Soemadio 1984: 18).

Dalam catatan sejarah baru Dinasti Tang (618-906) dikatakan bahwa kerajaan Kaling yang juga disebut Jawa, tecletak di lautan selatan, timur Sumatra dan di barat Bali. Sejak masa Chin-kwan (627--649) negara ini mengirimkan utusan dengan membawa hadiah, bersama-sama dengan To-ho-lo dan To-po-teng (Sumatra). Raja mereka dianugrahi hadiah balasan serta surat yang diberi cap kerajaan oleh raja Cina. Antara tahun 776-79 datang lagi tiga utusan yang juga membawa kiriman barang dari Kaling untuk raja Cina. Pada tahun 813 mereka menghadiahkan empat orang budak, burung-burung kakak tua dengan wama yang berbeda-beda, burung-burung yang berwama merah jambu (pinka birds), serta barang-barang yang bermutu tinggi lainnya. Raja Cina membalasnya dengan menganugrahkan mereka gelar Left Defensor, yaitu sebagai salah satu penjaga empat gerbang utama kerajaan. Utusan yang membawa hadiah dari Jawa kembali datang antara tahun 827 dan 835. Pada tahun 860 dan 873 mereka mengirim utusan dengan maksud mengadiahkan pemain-pemain musik wanita.

Dari uraian yang terdapat dalam Sejarah dinasti Sung (960-1279) diketahui bahwa Jawa terletak di laut selatan. Negeri ini menghasilkan emas, perak, cula badak, gading, lada, sulphur, dan sebagainya. Pada tahun 992 negeri ini mengirimkan dua orang duta yang membawa pesan bahwa mulai sekarang mengakui Cina kembali sebagai raja besar, dan berjanji bahwa negara mereka akan memberikan raja Cina kiriman barang-barang yang bermutu tinggi, seperti gading, mutiara, sulaman sutera, katun, cula badak, berbagai warna burung kakak tua, kulit-kulit penyu, anyaman rotan, dan sebagainya.

Uratan selanjut mengatakan bahwa setelah utusan mereka berlayar selama 60 hari, utusan ini tiba di wilayah Ting-hai (kepulauan Chusan), dimana pengawas perdagangan mengirimkan pesan kepada raja. Utusan ini memakai pakaian seperti orang Persia yang juga memberikan hadiah ke raja Cina sebelum kedatangan utusan ıni. Dengan dibantu oleh penerjemah, dikatakan pula bahwa ada seorang pedagang Cina yang memiliki banyak barang sering datang ke negerinya dan sekarang meminta tolong untuk dapat menghadap raja sambil membawakan barang-barang bermutu sebagai hadiah

Sehubungan dengan kedatangan utusan ini raja memerintah pesuruhnya untuk menjamu dengan baik, dan meminta meluangkan waktu mereka untuk tinggal beberapa hari, serta menghadiahkan mereka sejumlah mas, sutra, juga kuda-kuda yang baik dan sejumlah peralatan pe- rang sebanyak yang mereka mau. Pada tahun 1109 raja dari negeri Jawa mengirim kembali utusan dengan membawa hadiah untuk raja $\mathrm{Ci}$ na. Pada kesempatan ini raja Cina tersebut memerintahkan para pesuruhnya untuk mengadakan pesta seperti yang telah mereka lakukan dalam menyambut utusan dari Giau-chi (Annam Utara).

Dalam catatan Sejarah Dinasti Yuan (1280-1367) tidak didapatkan data mengenai adanya pengiriman upeti ataupun hadiah dari raja di Jawa, karena pada masa itu terjadi ketegangan politik antara Cina dengan Jawa sebagai akibat dari keinginan raja Cina yang ingin memperluas wilayah kekuasaan. Tetapi dalam catatan Sejarah dinasti Ming (1368-1643) tercatat adanya utusan yang membawa barang hasil produk lokal serta sepucuk surat yang ditulis pada seperangkat emas atas perintah raja Sri Pah-tala-po tahun 1370.

Pada tahun 1372, yaitu pada saat utusan raja Cina Chang K'o-ching kembali ke Cina, raja dari Jawa memberikan sejumlah barang berharga. Tahun 1377,1379 dan 1380 raja Cina menerima utusan yang membawa kiriman barang dari raja Jawa bemama Pa-ta-na-pa-na-bu. Tahun 1381 raja dari Jawa mengirim utusan yang membawa hadiah berupa 300 budak kulit hitam serta produksi lokal mereka. Setahun kemudian mereka mengirimkan kembali ratusan budak hitam pria dan wanita, delapan buah mutiara yang besar, serta 75000 kati lada. Kiriman untuk raja Cina berlangsung pada tahun 1393 dan 1394

Pada waktu raja Cheng-tsu naik tahta, beliau mengirim khabar ke negeri ini, dan tahun berikutnya 1403, ia mengirimkan wakil utusan dan pesuruh untuk mengirim hadiah kepada raja berupa sutera dan kain-kain kasa bersulam emas. Pada waktu utusan itu kembali, raja dari Barat, yaitu Tumapel (Tu-ma-pen), mengirimkan ucapan selamat untuk kaisar Cina, yang juga membalasnya dengan mengirimkan sida (budak) atas hadiah cap perak raja. Raja membalas ucapan terima kasih untuk cap kerajaan tersebut dengan mengirimkan produksi lokal negerinya

Raja dari wilayah Jawa sebelah timur pun mengirimkan utusan serta hadiah dengan maksud untuk mendapatkan pula cap kerajaan yang sama, dimana raja Cina mengirimkan utusan untuk membawakannya ke raja ini. Sejak itu dikatakan ada dua negara dari wilayah barat dan timur Jawa mengirimkan hadiah barang untuk raja Cina. Pengiriman utusan yang membawa barang untuk raja Cina dari raja Jawa ini terus berlangsung pada tahun-tahun berikutnya. Ada yang dikirim sekali setahun, kadang-kadang lebih. Tercatat bahwa pengiriman tersebut berlangsung pada tahun 1405, 1415, 1432. Tahun 1446 pengiriman hadiah barang ini semakin jarang 
Pada tahun 1499 kapal yang membawa utusan dari Jawa karam karena badai, hanya perahu yang membawa penterjemah saja yang tiba di Kanton yang disambut dengan "upacara kapal" (feast of board). Kemudian mereka dikirim kembali pulang dengan memberikan beberapa hadiah untuk penguasa mereka. Setelah itu, sedikit sekali utusan yang datang ke Cina dengan membawa hadiah barang.

\subsection{Negara Lain di Asia}

Uraian mengenai pengiriman utusan serta barang-barang bermutu tinggi dari negara-negara lain, seperti Annam, Kamboja, Champa, India, bahkan negerı Arab kepada Cina, diuraikan pula dalam buku Chau lu-Kua, catatan Ch'ien-Han shu, Ma-tuan-lin, dan lain-lain.

Negara bawahan Cina yang mengirikan upeti ke Cina yang ada dalam uraian Chau-jukua adalah negara di wilayah Tongkin. Sebagai negara bawahan Cina, pengiriman upeti dari Tongkin ke Cina berupa produksi lokal dikirim tahunan.

Mengenai negeri Annam dimana sebelah baratnya berbatasan dengan Yunan, sebelah timur dengan Chan-chong dan Kanton, pada awalnya mempunyai hubungan yang kurang dekat dengan Cina, tetapi sekitar tahun 950an, yaitu masa akhir raja Hien-to, Annam mengirimkan utusan serta barang ke Cina untuk yang pertama kalinya. Pengiriman ini terus berlangsung pada masa dinasti K'ien lung dan K'ien to (960-967), berupa produksi lokal yang bermutu tinggi, seperti gajah, getah pohon garu, rotan putih, katiun, anyaman bambu, cula badak, dan sebagainya. Seperti halnya negeri bawahan Sriwijaya, negeri bawahan Annam yang terletak di wilayah Panrang (pantai Kochincina) juga mengirimkan hasil tahunan mereka sebagai kewajiban ke negara Annam.

Lebih jauh lagi dikatakan dalam tahun ke-4 pemerintahan Yung-hi (987), Annam bersamasama Ta-shi (Arab) mengirimkan utusan dan membawa kiriman barang dari rajanya ke kaisar Cina. Dari catatan Chan-cho'ong dikatakan bahwa utusan yang me.mbawa kiriman barang ini berlangsung pada tahun 961, 962, 1086

Demikian pula halnya negara Burma, pada tahun pertama King-to (1004) mengirimkan utusannya ke Cina dengan membawa hadiah, bersama-sama dengan utusan dari San-fo-tsi dan Ta-shi (Arab), pada waktu mereka mendapat kesempatan untuk jadi saksi dalam Pesta Lentera (the Feast of Lanterns). Tahun-tahun Burma mengirim utusan dan barang ke Cina: 1106, 1007. 1020, 1030, 1042, 1050, 1053, 1056 dan 1061

Negeri India, yang telah lebih dulu menjalin hubungan dengan Cina dibandingkan dengan negara-negara Asia Tenggara, hanya di- uraikan sedikit. Pada masa pemerintahan raja chong-kuan (627-650) dan tien-shou (690-692) dari dinasti Tang, India mengirimkan utusan yang membawa hadiah barang untuk raja Cina. Pada catatan Ja-tung shu-chu dikatakan adanya pembelian singa oleh raja Cham pada tahun 1011. Raja ini bermaksud hendak mengirimkan sebuah hadiah yang menarik bagi kaisar Sung di Ciria. Singe ini dibawa melalui Palembang dari India oleh para pedagang Arab. Tahun berikutnya dikhabarkan pula bahwa utusan dari negara Annam memınta ijin raja Cina agar dapat melihat hadiah singa dari India tersebut.

Negeri timur tengah yang ada dalam uraian Chau-Jua-Kua yang juga mengirimkan utusan dengan membawa barang ke Cina adalah negeri Arab (Ta- shi). Sejak masa Yung-hui dari dinasti Tang (650--656) dikatakan bahwa negeri Arab selalu datang mengunjungi raja Cina dengan membawa hadiah barang. Pemberian hadiah ini masih terus dilanjutkan pada masa raja K'ai-pau tahun 968, dais pada tahun 971 bersama-sama dengan utusan dari Annam dan Jawa dikirim pula hadiah usituk Li-yu, pangeran dari Tang selatan di Kiang-Nang. Lebih lanjut diuraikan bahwa pangeran Ýu tidak mau menerima mereka, sehingga utusan-utusan tersebut menyerahkannya kepada raja. Pada masa shun-hua tahun 993, dikatakan bahwa negeri Arab ini langsung mengirimkan hadiahnya pada pejabat yang khusus mengurus pengiriman utusan bemama Li-a-wu di sebuah salah satu balairung istana bemama Chung-chong.

\section{Distribusi Barang yang Berlatar Politis}

Banyak data sejarah yang menyatakan adanya hubungan antara negara-negara di Asia Tenggara, terutama kepulauan Indonesia dengan Cina diawali dengan tukar-menukar barang melalui hubungan dagang. Keletakannya yang strategis di jalur lintas transportasi perdagangan laut antara India dan Cina, semakin meningkatkan hubungan antar negara-negara tersebut.

Pada mulanya raja-raja Cina memang kurang berminat terhadap wilayah di Asia Tenggara ini, karena Asia Tenggara dianggap wilayah yang kurang beradab yang terletak jauh dari pusat peradaban Cina di utara. Tetapi dengan tumbuhnya perdagangan maritim dari Asia Barat ke $\mathrm{Ci}$ na Selatan melaluı Indonesia, peranan hasil Asıa Tenggara dalam hubungan perdagangan dengan Cina turut berkembang pula. Meskipun demikian, tidak dapat dipungkiri India turut berperan dalam memberikan pengalaman perdagangan internasional bangsa Indonesia, dimana kedua negara ini telah lebih dulu berhubungan (Soewadji Sjafei 1977).

Pada perkembangan selanjutnya, terjadı satu hal yang penting dalam hubungan antara 
Indonesıa dan Cina, yaknı dengan adanya pelayaran langsung antara kedua tempat tersebut. Hubungan pelayaran itu dapat merupakan bagian darı hubungan pelayaran antara Asia Barat dengan Cina, tetapi juga dapat merupakan hubungan tersendiri antara Indonesia dengan Cina. Perkembangan jalur laut yang langsung ke Cina dimulaı pada awal abad $5 \mathrm{M}$ ini, membawa sesuatu kepentingan baru di pantai tenggara Sumatra yang juga merupakan jalur dagang dengan India dan Srilangka. Wolters (1974) memberı Istilah wilayah ini dengan sebutan "favoured coasf" pada masa awal perdagangan Indonesia. Dari pantaı inı rute pelayaran menuJu laut Cina selatan dimulai.

Keuntungan yang juga diperoieh dengan adanya jalur dagang yang berada serta melintasi vilayah !ndonesıa ini, memberikan kesempatan pada bangsa Indonesıa untuk mendapatkan kemahiran-kemahiran tertentu yang diperlukan agar dapat berhadapan dengan pedagang asing dengan taraf yang sama

T:dak dapat disangkal bahwa negeri Cina yang merupakan negara besar dan kuat serta menghasilkan banyak barang, khususnya barang dagangan. menguasal perdagangan internasıonal Hubungan dagang Cina dengan dunia luar sudah dirintisnya sejak berabad-abad sebelum masehi, terutama dengan negara-negara di Wilayah Asıa Barat, sampai ke Eropa (Groeneveldt 1960. 4-5) Kareria jalur perdagangan, terutama antara Asia Barat dengan Cina melewati bebeapa wilayah maritim maupun daratan di Asia Tenggara, maka daerah-daerah di Asia Tenggara pun secara langsung maupun tidak langsung turut ierlibat dalam pasaran internasional

Untuk turut serta berperan dalam jaringan Dasar itu balk negeri Cina maupun negara-negara laınnya tersebut berusaha untuk menciptakan Jalınan persahabatan dı antara mereka yang dianggap salıng memegang peranan penting Salah satu cara untuk saling menjaga serta nenıngkatkan hubungan antar negara-negara tersebut dengan melakukan tukar-menukar kiriman barang antara penguasa yang memegang tampuk pımpinan

Data yang ada dalam berita Cina menunjukkan bahwa tidak sedikit adanya pertukaran pengıriman barang antar negara-negara Asia Tenggara, India dan Cina dengan berbagai alasan, misalnya, pengirıman hadiah sebagai ucapan tahun baru, pengiriman utusan yang membawa barang-barang berriutu tinggi, seperti emas, perak, gading gajah, serta produk lokal lainnya dengan imbalan diberikannya nama untuk bangunan suci Buddha yang ada dinegaranya, diijinkan mengunjungi gunung suci yang ada di negeri Cina, mengunjungi gedung-gedung utama istana, ikut menyaksikan pesta-pesta khu sus istana, dan sebagainya.

Alasan ini pada dasarnya memiliki tujuan teitentu, yaitu adanya pemikiran ekonomis yang melatarı masing-masing negara yang terlibat dalam Jaringan pasar internasional tersebut untuk dapat membeli, menjual, menerima, menukar, serta yang lebih penting lagi mendapatkan keuntungan seoptimal mungkin. Begitu pula bag। negara Cina itu sendiri, dengan didasari pada pemenuhan kebutuhan pasaran dinegerı mereka akan barang-barang komoditi yang hanya bisa didapat dari negara-negara lain, seperti mas perak, parfum, bahan obat-obatan, dan sebagalnya ini: Cina pun membuka tangan dalam jalur persahabatan tersebut sesuai dengan peranan dan kepentingan masing-masing negara tersebut, dengan cara membalas kembali pemberian barang yang diterimanya. Bahkan balasan kembali barang-barang dari Cina tidak kalah berharganya, seperti seperangkat menunggang kuda dari emas kaın-kain sutera. bahkan peralatan perang yang bisa dimınta sesuai dengan keinginan dari utusan yang membawa kırımar: nadiah tersebut

Kajian dari sumber berita Cina lebih Ianjut memperlihatkan bahwa tindakan pengirıman utusan dengan membawa berbagai barang berkualitas tinggi, baik hasil produk negerınya. maupun barang berharga yang diperoleh dari negara laın. menunjukkan bahwa adanya tukar menukar pengirmman barang berharga bagi para raja bukkan nanya sekedar menciptakan jalur persahabatan dengan kelompok-kelompok yang dianggap kuat serta berperan dalam Jalur perdagangan tetapi dibarengi pula dengan tuJuan politis laınnya

Besarnya peran dalam pasar internasıonal wilayahnya yang luas menguasaı jalur perdagangan, serta sebagar negara kerajaan besar yang telah berdiri pada abad-abad sebelum masehi secara tidak langsung menjadikan negerı Cina diakuı dunia sebagai negerı yang penting Hal in dengan sendirinya memberıkan peluang bagi Cina untuk memiliki kewenangan dalam berbagaı segı, terutama dalam hal pemberıan ı, n untuk turut dalam kanca pasar internasıonal seita dapat melintasi jalur perdagangan baik darat maupun laut. Uraian mengenai permoho. nan diberinya sebuah surat yang diberı cap kerajaan Cina bagi utusan yang datang membawa kiriman barang berharga dari raja (uraian dalarr: catatan sejarah baru Dinasti Fang tahun 618 906), secara tidak langsung membuktikan adanya pengakuan ini.

Bahkan negara Arab yang menggantung kan perniagaannya melalul jalur sutera dengan Cina, ikut pula dalam arena pergaulan semacam ini dalam usaha membuka hubungan dengan Cina serta wilayah-wilayah lain yang dilalui jalur 
perdagangan tersebut. Karenanya, tidaklah heran bila negara Arab pun sering mengirimkan utusan ke Cina untuk memberikan hadiah-hadiah khusus dari hasil bumi, hasil tambang, produk-produk lokal yang sebagian besar berupa jenis barang yang* biasa diperdagangkan, dengan tujuan politis yaitu tetap memiliki ijin melintasi bahkan masuk ke dalam jaringan "pasar" internasional, serta jaminan perlindungan.

Tujuan politis lainnya yang juga tidak kalah penting dalam pergaulan antar negara melalui tukar menukar pengiriman barang dengan Cina ini, yaitu adanya perlindungan serta jaminan rasa aman dari gangguan negara lain yang berusaha untuk merebut kekuasaan mereka. Hal ini terlihat dari catatan Cina tahun 430 yang menceritakan adanya utusan yang datang dari Holotan sebuah negeri di She-p'o dengan membawa sepucuk surat dari rajanya yang berisikan berita bahwa negeri mereka diancam oleh negaranegara tetangganya, dan memohon agar raja di Cina memberi perlindungan dari jauh, serta berharap agar Cina mengirimkan utusan ke negara-negara tersebut untuk minta agar mereka Jangan mengancam Ho-lo-tan; serta uraian mengenai kedatangan utusan raja Sriwijaya tahun 992 dengan membawa surat yang mengatakan bahwa negerinya diserbu oleh kerajaan She-p'o dan memohon bantuan untuk dapat mengatasınya.

Karena peran serta kedudukan Cina yang demikian, adapula pengirıman barang dengan alasan hadıah, beitujuan untuk mendapat pengakuan serta restu dari raja Cina. Selain sebaga pemberitahuan adanya negara serta raja baru kepada C.ina, pengakuan darı Cina bagi negara yang relatif masih baru inı dianggap dapat me. naikkan derajat negara tersebut, baik bagı rakyatnya maupun dalam pergaulan internasional. Inı pula salah satu tujuan politıs adanya pengırıman utusan yang membawa barang-barang berharga yang diberikan kepada raja Cina

Dengan dilatarı berbagai tujuan politis inilah. tukar-menukar pengiriman barang ke dan dari negara Cina terus-menerus berlangsung. Dengan sendirınya. adanya alasan tukar-menukar kiriman barang yang berlatarkan tujuan politıs inı, memberikan keuntungan besar pula bag negara Cina tersebut, balk dari segi ekonomı maupun politik.

Dalam kenyataannya, tidak semua negara dapat ikut serta dalam pasar internasıonal tersebut. Ada negara-negara yang karena keletakkannya yang kurang menguntungkan, yaitu tidak pada jalur dagang serta kecilinya wilayah kekuasaan mereka, mengakıbatkan mereka hanya dapat terlibat pada tahap perdagangan lokal saja. Negara-negara inilah yang demi kelangsungan negerinya, menggantungkan hidup pada negara- negara besar di dekatnya. Karena keadaannya sebagai negara bawahan itulah, negara-negara kecil ini mempunyai kewajiban dalam pengiriman barang sebagai upeti kepada penguasanya. Selain demi kelangsungan pemerintahannya, negara-negara kecil inipun berharap untuk dapat ikut dalam memasarkan lebih jauh lagi hasil produksi lokal mereka ketingkat pasaran lebih tinggi. Karenanyalah, negara-negara inipun tercatat dalam berita Cina karena mengirimkan barang hadiah untuk raja $\mathrm{Cina}$

\section{Penutup}

Negeri Cina yang merupakan kerajaan besar sudah dikenal serta menguasai perdagangan khususnya perdagangan melalui jalur sutera, sehingga dianggap memiliki kewenangan yang lebih dibandingkan negara-negara Asia lainnya. Tidak sedikit negara-negara di Asia bahkan Arab, mengirim utusan dengan membawa berbaga barang berharga untuk raja Cina, walaupun hanya sebagian kecil yang dimaksudkan sebagaı persembahan atau upeti.

Bagi negara-negara yang juga cukup besar dan kaya, seperti Sriwijaya, Jawa, India, Campa, serta Arab, pengiriman barang ke negerı Cina secara garis besar bertujuan politis yang didasari atas faktor kebutuhan agar dapat berperan serta dalam jaringan pasar internasional, memiliki keleluasaan dalam penggunaan jalur sutera yang berada di wilayah kekuasaan Cina, serta mendapat perlindungan dari negara-negara yang kemungkinan berniat untuk memperluas wilayah sampai ke negerı mereka.

Adapula negara yang mempunyaı tujuan politis lain dalam kegiatan tukar-menukar penglriman ke dan darı negeri Cina yaitu sebagal legıtimasi. Pada kerajaan-kerajaan yang sudah lama berdiri, masa penggantian seorang raja adalah masa kelemahan, sejenis 'power vacuum', lebih. lebıh pada akhır pemerıntahan seorang raja yang sebelumnya telah menguasal kerajaan selama puluhan tahun. Dalam hal ını, pengakuan kedaulatan serta keberadaannya oleh negerı Cina akan memperkuat kedudukannya dimata rakyatnya dan teristımewa darı negara-negara laın yang mempunyai hubungan dengan Cina.

Bagı negara-negara yang benar-benar mengırimkan barang kepada raja sebagaı upetı. adalah negara-negara kecil dimana kelangsungan pemerintahannya bergantung pada negara besar. Sebagal kompensasınya, negara-negara kecil yang bergantung pada negara besar sepertı Sriwijaya, Annam, serta Cina, berkewajıban mengirimkan barang, terutama dari produk lokal mereka dalam bentuk upetı.

Pada bagian akhır kajian data darı sumber berita Cina inı, dapat diketahui, distribusı atau penyebaran barang yang berasal dari dan/atau 
yang melalui Asıa Tenggara, ternyata tidak hanya berupa dan melalui cara perdagangan tetapi juga mempunyai latar politis

\section{KEPUSTAKAAN}

Bambang Sumadio,(ed).1984, Sejarah Nasional Indonesia II, Jakarta. Balai Pustaka

Bugie Kusumohartono,1985, Strategi Adaptasi. Lingkungan. Pola Ekonomi dan Pelestarian Kekuasaan. Paparan Mengenai Be-berapa Data Jaman Kuna, Berkala Arkeologi VI (2) Yogyakarta:Balai Arkeologi Yogyakarta him. 33-47.

Groeneveldt.WP, 1960,Historical Notes on Indonesian and Malaya Compiled from Chinese Sources. Djakarta: Bhratara

Hall, DG 1960, A History of South East Asia. London: Macmillan and Co Ltd

Hirth. F. dan WW Rockhill, (ed):1966, Chau Ju Kua: His work on the Chinese and Arab trade in the Twelfth and Thirteenth Centuries, entitled 'Chu-fan-chi'. Amsterdam: Oriental press

NJ PS Kusumosutojo, (terj.),1972, Sumatera dan Pelajaran di Samudera Hindia Oleh:C Nooteboom. Djakarta: Bhratara

Soewadji Sjafei, 1977. Pengaruh Kebudayaan India di Asia Tenggara, Berita Antropologi: Majalah limu Sosial dan Budaya IX, no. 32 Jakarta:Penerbit UI.

Wheatley. Paul. 1966, The Golden Khersonese: Studies in the Historical Geography of the Malay Peninsula before AD 1500 Kuala lumpur: University of Malaya Press

Wolters OW 1974, Early Indonesian Commerce: A Study of the Origins of Srivijaya Ithaca dan London Cornell Univ. Press 